\title{
Prácticas Asociacionistas como estrategias de revitalización de la imagen de marca de un distrito turístico cultural. Caso de Barrio de Las Letras en Madrid y Barrio Italia en Santiago de Chile
}

\section{Association practices in historical districts as facilitators of destination brand image. The case of Las Letras Distric, Madrid \& Italia District, Santiago of Chile}

\author{
Stefania Pareti’ ๑ y Blanca García Henche ${ }^{2}$ ๑
}

\begin{abstract}
RESUMEN
Para construir y desarrollar la imagen de marca de un destino turístico, es esencial contemplar la colaboración de todos los stakeholders que operan en dicho destino.

Sobre la base de las tradiciones y el patrimonio cultural, las pequeñas empresas pueden transformar los espacios urbanos con un impacto directo en el rendimiento de las organizaciones de dicho espacio, creando marca identificativa y convirtiendo esos espacios en "barrios-destino"

Esta investigación pretende analizar el rol que desempeña la colaboración entre pequeños emprendedores en la creación de una marca destino turístico, realizando un estudio comparativo del Barrio de las Letras (Madrid) y Barrio Italia (Santiago de Chile).

Para alcanzar los objetivos se han obtenido datos de la oferta cultural, comercial y turística en dichos barrios.

Los resultados muestran que las marcas consiguen la identificación de "barrios históri-

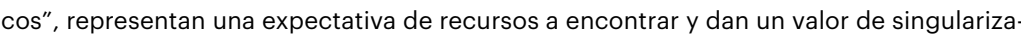
ción a los barrios.
\end{abstract}

Palabras clave: Barrios destino, marca destino turístico, regeneración del tejido comercial, asociacionismo, marketing turístico.

\section{ABSTRACT}

To build and develop the brand image of a tourist destination, it is essential to contemplate the collaboration of all the stakeholders that operate in that destination. Based on traditions and cultural heritage, small businesses can transform urban spaces with a direct impact on the performance of the organizations in that space, creating an identifying mark and turning those spaces into "districts-destination" This research aims to analyze the role of collaboration among small entrepreneurs in the creation of a tourism destination brand, making a comparative study of Las Letras District (Madrid) and Italia District (Santiago of Chile). In order to achieve the objectives, we have obtained data on the

Facultad de Economía y Negocios, Universidad Andrés Bello. Correo electrónico: s.pareti@uandresbello.edu 
cultural, commercial and tourist offer in these districts. The results show that the brands get the identification of "historic districts", represent an expectation of resources to find and give a value of singularity to the districts.

Keywords: Destination district, tourist destination brand, regeneration of commercial network, associationism, tourism marketing.

Desde los años 60 y hasta hoy en día, la evolución del sector turístico ha sido considerable y su función en la transformación de las ciudades es cada vez más marcada. El turismo urbano juega un papel fundamental ante esta transformación, ya que a medida que la globalización va acaparando las ciudades, la competencia entre las mismas es cada vez mayor, y para enfrentarse a ella es necesario ser diferente y promover de la mejor manera posible, aquello que la ciudad puede ofrecer al turista.

En este contexto, hay que destacar cada vez más la importancia del marketing urbano, explicado por Castelleti y D’Acunto (2009) como la investigación, valorización y promoción del territorio, para fomentar y sostener el desarrollo local, basándose en aquello que lo hace único y todo esto desde una perspectiva global. Es, por tanto, de una herramienta que permite la creación de la imagen de una ciudad, imagen capaz de proporcionar a su vez una serie de beneficios a la misma, mediante el aprovechamiento de ventajas socioeconómicas.

Añadido a la idea de marketing urbano y geomarketing, surge un nuevo concepto cuya influencia está en continuo auge, el City Marketing entendido como la fidelización tanto de la población local, como de la temporal (turistas, empresas e inversores) y como forma de impulsar la ciudad hacia el exterior (Albornoz et al., 2010). En este sentido, cabría diferenciar entre el marketing urbano y el City Marketing, ya que mientras el primero se refiere a la ciudad en su conjunto, el segundo se centra en lo que viene ser el centro de la ciudad, su comercio, su cultura y sus residentes.

Es por todo ello, el diseño de una marca urbana en base a sus procesos de identidad y a su imagen, es el motor principal del desarrollo urbano. Además, es lo que permite atraer inversores y turistas, teniendo siempre en cuenta los impactos que esto puede generar sobre los residentes.

Por otra parte, el consumidor turístico actual busca ser protagonista de su propia experiencia (Hall \& Weiller, 1992; Robinson \& Novelli, 2005). Los turistas empiezan a mostrar interés por el patrimonio cultural y por el consumo activo de cultura en unas ciudades renovadas y dispuestas a satisfacer esas necesidades. Así, el nuevo tipo de turista, no se conforma con los modelos turísticos tradicionales y busca nuevas experiencias, busca emocionarse y vivir la ciudad disfrutando de ella como un todo. Se trata, por tanto, del consumo de una ciudad diseñada en base a todas las características y elementos que la componen, desde sus barrios, sus monumentos, comercios, hostelería y alojamiento, hasta las costumbres locales, la cultura y la gente.

El mundo del turismo sigue cambiando día tras día, cosa que hace necesaria la introducción de nuevas estrategias de marketing, adaptadas a estos cambios. Es por ello por lo que queda justificado introducir el concepto de Marketing experiencial, como un valor añadido al concepto de marketing urbano, ya que, al analizar los gustos de los consumidores, no basta con tener unas estrategias claras de desarrollo y promoción urbana, si no se es capaz de satisfacer esos gustos mediante experiencias únicas, transformadoras y diferentes. 
Por otro lado, el turismo al ser considerado a su vez una actividad con contenido social, ha generado amplias aristas de desarrollo en cuanto al concepto de productos turísticos (Barbieri, Almeida Santos \& Katsube, 2012; McGehee \& Andereck, 2009; Wearing, 2001).

El objetivo principal de este trabajo de investigación es desarrollar un estudio de caso comparativo en el Barrio Italia, Santiago de Chile y Barrio de las Letras para explorar cómo el asociacionismo y las redes generan una sinergia entre las partes que lo conforman, generando un sello único e imposible de replicar debida a la diferenciación e imagen de marca desarrollada. La razón de la elección de dichos barrios es que ambos se encuentran en el centro histórico de una gran ciudad, basan su estrategia de diferenciación en los recursos culturales y comerciales, pero dichos barrios se encuentran en diferentes fases de su ciclo de vida como destinos turísticos lo que no siempre sirve para explicar la complejidad urbana y la vitalidad de la función turística de los destinos (Romero, et al. 2020).

La imperiosidad y justificación de poder llevar a cabo la presente investigación, se sustenta con un espacio que aún no está cubierto y existe una gran oportunidad de investigación, ya que no existe a la fecha metodologías sistemáticas para gestionar adecuadamente patrimonio cultural junto a desarrollo territorial y urbano sustentable (Bandarin \& Van Oers, 2012), referenciado al posicionamiento de marca en los barrios históricos.

\section{Antecedentes}

Al analizar estudios e investigaciones respecto a marketing cultural y de experiencias vinculado al turismo cultural y patrimonial, se observa que resulta muy escasa la literatura que vincula la metodología de redes de asociación en el ámbito del turismo cultural en las ciudades junto a estrategias de marketing relacionadas con la imagen de marca, que se pueden llevar a cabo para potenciar la colaboración y sustentabilidad entre las partes que la componen.

Dado lo anterior el marco teórico se abordará a través de la revisión de conocimiento y modelos relacionados con dos ámbitos principales: 1) Construcción y desarrollo de imagen de marca en destinos turísticos y 2) Teoría de redes y análisis de sistemas para comprender prácticas de cooperación.

\section{Construcción y desarrollo de imagen de marca en destinos turísticos}

La gestión de la marca-destino es esencial para aumentar la demanda turística. La herencia intangible junto con aspectos patrimoniales puede ser relevantes para la generación de una marca-destino que posicione los barrios históricos en lugares a demandar por los consumidores turísticos. En este aspecto el fin de esta investigación, es tratar de explicar como el desarrollo de marcas urbanas y la creatividad son motores para que las ciudades logren desarrollar el turismo cultural creativo, diferenciado del turismo cultural tradicional. El trabajo realizado en Barrio Italia y Barrio de las Letras servirá para describir la creación de una marca de "barrio destino" dentro de los destinos de turismo urbano. 
Según Dichter (1985), el concepto de imagen es atribuible a productos, países, lugares, ya que no describe los rasgos o cualidades individuales, sino la impresión total que una entidad produce en las mentes de los demás. La imagen a su vez se plasma en todos los elementos de un lugar o una compañía.

Sánchez y Bigné (2001) afirman que la aplicación del marketing a los destinos turísticos es fundamental considerar la percepción que los turistas tienen sobre dicho destino. Así, es necesario comprender cómo la identificación que tienen los consumidores con diversos destinos va a estar directamente relacionada con la comunicación que tenga hacia la marca de destino (Bigné, García \& Blas, 2009; Heere, Walker, Yoshida, Ko, Jordan \& James, 2011). Es por ello por lo que un centro histórico que busca desarrollar una imagen de marca debe trabajar arduamente la búsqueda de un consumidor que se identifique con la identidad del destino.

Otros autores, como Mueller y Schade (2012), aluden a la importancia de potenciar una identidad común entre los stakeholders para generar identidad de un lugar y crear una marca de destino. Se ha de tener en cuenta que quién visita un lugar recibe el destino como un todo, por lo que es necesario que sus partes estén alineadas para transmitir un mismo mensaje y así posicionar de un mismo modo al lugar. Esta teoría se puso a prueba en el caso de Bremen, Alemania dónde se logró consolidar un destino con una imagen de marca clara.

Vidal (2008) desarrolla un estudio respecto a la intangibilidad del turismo histórico-patrimonial y su identidad. Así, la herencia intangible de los destinos tiene el poder de construir una identidad cosmopolita, la globalización ayuda a que eso se cumpla al unir aspectos del patrimonio intangible junto con las identidades personales.

Kotler y Gertner (2002) desarrollan el marketing de lugar junto a una perspectiva de gestión de marca, ya que al tener un desarrollo eficiente de ello ayuda a aumentar el número de visitas turísticas, aumentar la inversión e incrementar el comercio. Konecnik y Chernatony (2013) en el caso de Eslovenia, desarrollan y aplican un modelo de identidad de marca de lugar, el cual integra una mirada de marketing junto al turismo, teorías sociológicas y la participación de los stakeholders más relevantes para lograr tener una mirada heterogénea del fenómeno.

Hanna y Rowley (2011) aluden a la idea de desarrollar modelos estratégicos de marcas de destino con foco en la evaluación de la marca de lugar, la gestión de stakeholders y las comunicaciones de marca.

Warnaby y Medway (2013) desarrollan la idea de marketing de destino como narrativas en los destinos. Estos deben considerar qué se va a comercializar, quiénes lo llevarán a cabo y finalmente cómo. Ya que los destinos, son lugares dinámicos comprendidos por elementos tangibles e intangibles.

Pero, se ha de considerar que una gestión de marcas de ciudad va más allá de logos, ya que las ciudades, si se manejan adecuadamente son un activo altamente valioso para la comunidad, por lo cual debe existir y desarrollarse una gestión integral de ello (Ashworth \& Kavaratzis, 2009). 
Vanolo (2008) desarrolla un caso empírico en Turín para explicar cómo el desarrollo de marcas urbanas y la creatividad son motores para que ciudades que son principalmente de carácter industrial, logren explorar y desarrollar turismo cultural y urbano. En ese caso particular se expone el caso de intervenciones creativas como iluminar la Mole Antonelliana con la serie de Fibonacci y los colores de la bandera italiana con una activación que se denominó "Serie de Artista". Siguiendo la misma línea de investigación, Bayliss (2007) realiza un estudio en Copenhague dónde se evidencia que trabajar junto a la creatividad se tradujo en una acción estratégica para actuar en pos del desarrollo de destinos, por lo que la creatividad e innovación debe estar contemplada en la planificación de ciudades, ya que fortalece la industria creativa local generando interés internacional de visitas turísticas y de la clase creativa además de inversión. Zencker (2009) complementa lo anterior, exponiendo que se debe definir cuál realmente es el segmento al aludir al concepto de clase creativa como segmento objetivo para el desarrollo de marca de destino, dónde se fomenta principalmente la diversidad y el urbanismo.

Manejar marcas de destino resulta complejo, para ello Hankinson (2007) desarrolló un modelo de gestión, basado en: "un fuerte liderazgo y visión, una cultura organizacional orientada a las marcas, alineación y coordinación departamental, comunicación fluida entre los diversos stakeholders y fuertes partnerships".

Chen y Tsai (2007) explican cómo la imagen y evaluaciones que se tenga de un destino puede afectar la intención y comportamiento de compra, siguiendo la línea del paradigma "calidad-satisfacción-intención de compra", se demostró que la intención de compra en cuanto a un destino viene dada por "calidad del viaje, valor percibido, satisfacción, intención de compra". Por otro lado, Qu, Kim \& Im (2011) para complementar lo anterior, desarrollaron un modelo de marcas de destino dónde integran el concepto de marca y por otro lado de imagen de destino.

San Martín y Rodríguez del Bosque (2008) exploraron el componente afectivo y cognitivo hacia imágenes de destino, junto con la importancia de comprender la psicología inherente en el proceso, ya que una imagen de destino es un concepto de carácter multidimensional, dónde se entremezcla el aspecto cognitivo y afectivo del consumidor, lo cual a su vez se vincula con la psicología de ello.

Hosany, Ekinci y Muzzafer (2007) desarrollan el concepto de imagen de destino y personalidad de destino como elementos altamente correlacionados, además prueban que los turistas al evaluar destinos vinculas características individuales de tipo cognitiva, afectiva y de su personalidad. Por lo cual, al generar planes, resulta evidente el considerar dichas variables.

Ekinci y Hosany (2016) desarrollan el concepto de personalidad de marca en destinos turísticos, para ello los destinos pueden realmente desarrollar personalidades y con ello diferenciarse, los turistas suelen reconocer a los destinos principalmente por tres factores: "sinceridad, entusiasmo y cordialidad", por lo cual el percibirse como una personalidad con imagen positiva, favorece las visitas y recomendaciones de los destinos.

Por otro lado, Richards (2016) desarrolla la idea de la relevancia que tiene la creatividad en el turismo cultural, pero no sólo puesto en lo tangible sino también en actos intangibles que creen 
valor actuando en pos de generar ciudades o clases creativas a su vez el turismo cultural creativo presenta una diferenciación alta respecto al turismo cultural tradicional.

Por tanto, una vez realizada una revisión de la importancia de la creación de imagen de marca para los destinos turísticos, se puede concluir que existen algunos factores críticos de éxito en el desarrollo de marketing de destinos: se debe trabajar en fortalecer una orientación estratégica, identidad e imagen de destino, incorporar a los diversos stakeholders e implementar y monitorear marcas trabajando sobre la singularidad. (Baker \& Cameron, 2008).

Todo lo anterior si es analizado y llevado a la práctica de modo colaborativo y planificado, puede apoyar a generar una imagen de marca o destino bien percibida y posicionada por los consumidores. El trabajo de investigación realizado en Barrio Italia y Barrio de las Letras viene a describir esa colaboración y planificación para la creación de una marca de "barrio destino" dentro de los destinos de turismo urbano.

La creación de las marcas Barrio de Las Letras y Barrio Italia conciben los barrios/destino como una marca, buscando la consecución de los siguientes objetivos, tal como analizaban Ruiz, Olarte e Iglesias (1999):

- Identificación de la zona o territorio o barrio de Madrid y Santiago de Chile.

- Utilidad de selección o elección por parte de los usuarios.

- Garantía: la marca representa una expectativa de recursos a encontrar por parte de los posibles consumidores.

- Valor de personalización: este valor se consigue en los dos barrios gracias a la existencia de pequeños comercios, anticuarios, etc.

- Valor lúdico.

Bajo las marcas Barrio de Las Letras y Barrio Italia, se busca crear una marca cuya finalidad es promocionar el atractivo de un barrio del centro de Madrid y Santiago de Chile e impulsar la actividad cultural, comercial y de ocio de este.

\section{Teoría de redes y análisis de sistemas para comprender prácticas de cooperación y asociacionismo}

La cooperación y las redes son un verdadero multiplicador de oportunidades en el sector turístico, creando marca debido a la cooperación de todos los stakeholders involucrados en un área geográfica. La presente investigación pretende explorar cómo la asociación de pequeñas empresas y las redes creadas entre los miembros asociados permiten la transformación de una zona comercial, creando una imagen de destino y aumentando el valor turístico del territorio y de los bienes del barrio, analizando el caso de Barrio Italia y Barrio de las Letras.

El trabajo asociacionista y cooperativo resulta fundamental para generar y consolidar una imagen de destino. La identidad de un lugar, junto a la eficiencia de los emprendedores que proliferan en el lugar y soportan las influencias que se generan y existen en la comunidad, son fundamentales para crear un sistema que se mantenga en el tiempo (Hallak, Brown \& Lindshay, 2012). 
Crnovrsaint, Muelder, Faris, Felmlee y Ma (2014) describen la relevancia de trabajar junto a la teoría de redes, ya que resulta de alta utilidad para analizar redes sociales que comúnmente están formadas por alto número de partes, nodos y bordes que sin una teoría base resultaría muy complejo analizar y observar visualmente. Esta teoría es comúnmente utilizada en las ciencias sociales, físicas y biológicas para generar mediciones que se suelen tangibilizar en sociogramas o diagramas que ilustran diversas situaciones en grafos.

Lemmetyinen y Go (2009) aluden a potenciar algunas características que actúen en pos de la creación de identidad, tales como potenciar los procesos con componentes de creación de valor y generar una identidad de marca consensuada y compartida en la comunidad que se conforma. Es evidente que, si cada parte actúa a modo aislado, no se genera un sistema, sino que serían meras partes sin un poder claro, por actuar a modo aislado y parcelado.

Sotiriadis y Loedolff (2015) enfatizan en la importancia de la oferta comercial y emprendedora vinculada al turismo que debe potenciar las prácticas colaborativas para resultar más competitivas. Para complementar lo anterior Merino-Rodríguez y Pulido-Fernández (2016) ponen el énfasis en la importancia de tener una mirada sistémica al hacer alusión a la gestión y comercialización turística. Por ello, las practicas colaborativas pueden suponer una estrategia de marketing urbano como integrantes de la generación de una imagen de marca de los destinos turísticos.

La cooperación y las redes son un verdadero multiplicador de oportunidades en el sector del turismo (Mendonça, Varajão \& Oliveira, 2015), ya que ayudan a potenciar la transferencia y fortalecimiento de conocimiento (Glückler, 2020; Zach \& Hill, 2017; Baggio \& Cooper, 2010).

El trabajo colaborativo resulta ser percibido de éxito por parte de los miembros que lo conforman (Varda \& Retrum, 2015), creando una imagen de marca positiva e identificativa del lugar, como ocurre en distritos turísticos como Le Marais en Paris, Nørrebro en Copenhague, Amsterdam Noord en Amsterdam o Dalston, en Londres.

Arnaboldi y Spiller (2011) analizan los destinos culturales con la teoría de actores-redes y la colaboración entre stakeholders en un nivel, lo que demostró que planificaciones rígidas no son viables de llevar a cabo, pero sí se puede trabajar en una mirada que busque alinear a los diversos actores, construir hechos mostrando experiencias pasadas que evidencien los riesgos y oportunidades existentes y hacer circular las ideas a través de la identificación de oportunidades, involucrando a los stakeholders.

Timur y Getz (2008) apelan que un desarrollo de turismo urbano está directamente relacionado con una de redes que incorpore y gestione a los stakeholders involucrados, se debe además analizar el vínculo existente entre los cluster de la industria, el gobierno y la comunidad en cuestión. Graci (2013), por su parte, genera un vínculo directo entre desarrollo de turismo sustentable y colaboración y asociacionismo, para ello se generó un estudio en la isla de Gili Trawangan en Indonesia para analizar la protección de la isla junto a todos sus recursos a través de la colaboración, asociacionismo y redes generadas entre las partes que forman el destino, lo cual resultó ser un mecanismo para mantener la supervivencia de la isla y desarrollarla a modo sustentable. 
Existen diferentes estudios sobre asociacionismo e imagen de marca de los destinos turísticos, entre los que cabe destacar:

- Rinaldi y Cavicchi (2016). Desarrollaron un estudio longitudinal en Italia respecto a comportamiento cooperativo y marca de destino, un caso de estudio se llevó a cabo en Marque potenciando el comercio agroalimenticio y de manufactura a través de prácticas cooperativas, donde el tener una visión común resulta fundamental para trabajar en conjunto, lo cual, a su vez, toma tiempo y si hay relaciones contractuales de por medio suele ser más simple al inicio de la conformación de la red.

- Perles-Ribes, Rodríguez-Sánchez y Ramón-Rodríguez (2015). Estudiaron si es necesaria la conformación de un cluster para generar éxito en un destino turístico, para ello se analizó el caso de Benidorm, dónde se comprobó que más allá de la existencia de un cluster, lo que es necesario es generar alianza y cooperación entre el ámbito tanto público como privado y poder así generar estrategias comunes que generen ventajas competitivas.

- Jesús y Franco (2016). Revisaron las redes de cooperación en turismo, generando estudio en hoteles y establecimientos de turismo rural en Portugal logrando probar que los resultados obtenidos trabajando a modo colaborativo fueron mayores que trabajando a modo aislado.

- Mariani (2016), incorpora la variable de coordinación como relevante para el trabajo en red en el sector turístico, la coordinación dada por contratos y aspectos legales entrega mayor eficiencia en la red, lo cual se puso a prueba en el Festival de Noche Rosada en Italia.

- D`Angella y Go (2009) realizaron un análisis de la cooperación entre la gestión organizacional de destinos y firmas del rubro turístico y para ello, estudiaron los casos de Viena y Barcelona dónde se demostró la importancia de la inclusión social como facilitador de la coordinación de la red que permite reducir conductas de no colaboración y potenciar la estabilidad de las relaciones.

- Duarte Alonso (2015) realizó un análisis del caso de Córdoba, España, dónde a través del trabajo colaborativo entre diversos stakeholders se ha logrado consolidar un destino entendido como destino turístico cultural e ir un paso más allá de destino de sol y playa.

- Chaterina y Zorrilla (2005), desarrollan un trabajo respecto al comercio minorista en Bilbao para entregar estrategias para alentar al asociacionismo e incrementar el desempeño y aumentar así la competitividad.

La mayor parte de los estudios aluden a la importancia del aporte individual para generar energías positivas sobre los demás individuos generando un desempeño global positivo de todo el sistema del que los individuos forman parte.

En el caso de los barrios que ocupan el presente estudio se trata de analizar cómo se trabaja esa sinergia para generar una imagen de marca basada en la singularidad de los barrios analizados. Así, a presente investigación pretende explorar cómo la asociación de pequeñas empresas y las redes creadas entre los miembros asociados permiten la transformación de una zona comercial, creando una imagen de destino y aumentando el valor turístico del territorio y de los bienes del barrio, analizando los casos de Barrio de Las Letras, en Madrid, y de Barrio Italia, en Santiago de Chile. 


\section{Material y Métodos}

En la investigación se han utilizado fuentes primarias y secundarias. En primera fase del proyecto, se realizó una revisión de la literatura y de fuentes secundarias, respecto a los modelos de gestión urbana, el asociacionismo y turismo experiencial.

Seguidamente, se ha recurrido a fuentes primarias de información, para así obtener de primera mano, datos sobre las características de la oferta cultural, comercial y turística del Barrio de Letras y de Barrio Italia, por medio de un modelo de entrevista a varios emprendedores y gerentes de las dos asociaciones. Dichas entrevistas fueron relevantes para conocer las dinámicas y procesos sociales y cómo éstos impactan en el fenómeno que se está estudiando y se utilizaron para la elaboración de un cuestionario.

La investigación primaria cualitativa se basa en entrevistas realizadas hacia miembros del directorio de la Asociación de Comerciantes de Barrio Italia y Barrio de las Letras. El diseño y la aplicación de la encuesta personal a los emprendedores/comerciantes fue administrada en el período comprendido entre los meses de noviembre a diciembre de 2015 en el Barrio de Las Letras de Madrid y en los meses de abril y mayo de 2017 en Barrio Italia en Santiago de Chile.

Las unidades muestrales consideradas para el análisis son emprendimientos, relacionados con el sector de la moda y textil, galerías de arte, librerías, antigüedades, decoración, hotelería, hostelería y restauración, entre otros.

Cuadro $\mathrm{N}^{\circ} 1$

Ficha técnica de la investigación primaria

\begin{tabular}{|c|c|c|}
\hline & $\begin{array}{l}\text { BARRIO DE LAS LETRAS } \\
\text { (Madrid) }\end{array}$ & $\begin{array}{c}\text { BARRIO ITALIA } \\
\text { (Santiago de Chile) }\end{array}$ \\
\hline Universo & $\begin{array}{c}\text { Unidades comerciales del Barrio } \\
\text { de las Letras. }\end{array}$ & $\begin{array}{c}\text { Unidades comerciales del Barrio } \\
\text { Italia, Santiago de Chile. }\end{array}$ \\
\hline Área Geográfica & Madrid, España. & Santiago, Chile. \\
\hline Muestra & $\begin{array}{c}187 \text { encuestas válidas (de los } 301 \\
\text { comercios del barrio). }\end{array}$ & $\begin{array}{c}198 \text { encuestas válidas (de los } 265 \\
\text { comercios del barrio). }\end{array}$ \\
\hline $\begin{array}{c}\text { Procedimiento de } \\
\text { Muestreo }\end{array}$ & Muestreo de Conveniencia. & Muestreo de Conveniencia. \\
\hline Error Muestral & $\begin{array}{c}+/-4 \% \text { para un intervalo de } \\
\text { confianza del } 95 \% \text { bajo la } \\
\text { hipótesis de } p=q=0,5\end{array}$ & $\begin{array}{l}+/-4 \% \text { para un intervalo de } \\
\text { confianza del } 95 \% \text { bajo la } \\
\text { hipótesis de } p=q=0,5\end{array}$ \\
\hline $\begin{array}{l}\text { Técnica de recogida de } \\
\text { información }\end{array}$ & $\begin{array}{l}\text { Encuesta personal administrada } \\
\text { a los emprendedores/ } \\
\text { comerciantes del área comercial } \\
\text { de barrio Italia a través de un } \\
\text { cuestionario estructurado. }\end{array}$ & $\begin{array}{l}\text { Encuesta personal administrada } \\
\text { a los emprendedores/ } \\
\text { comerciantes del área comercial } \\
\text { de barrio Italia a través de un } \\
\text { cuestionario estructurado. }\end{array}$ \\
\hline $\begin{array}{l}\text { Período de recogida de } \\
\text { información }\end{array}$ & Noviembre-Diciembre 2015. & Abril -Mayo de 2017. \\
\hline $\begin{array}{l}\text { Tratamiento de la } \\
\text { información }\end{array}$ & $\begin{array}{l}\text { Análisis univariable y bivariable } \\
\text { descriptivo. }\end{array}$ & $\begin{array}{l}\text { Análisis univariable y bivariable } \\
\text { descriptivo. }\end{array}$ \\
\hline $\begin{array}{l}\text { Procesamiento de la } \\
\text { información }\end{array}$ & Dyane, Excel, SPSS 12.0. y Gephi. & $\begin{array}{l}\text { Dyane, Excel, SPSS 12.0. y } \\
\text { UCINET. }\end{array}$ \\
\hline
\end{tabular}

Fuente: Elaboración propia (El cuestionario en esta investigación consta de dos secciones: a) perfiles de los comerciantes y las acciones comerciales y b) metodología de redes sociales). 


\section{Resultados}

Los resultados muestran que las marcas consiguen: (1) la identificación de un territorio/barrio como "barrios históricos, (2) representan una expectativa de recursos a encontrar por parte de los posibles consumidores (recursos relacionados con la historia, el arte y el comercio tradicional) y (3) consiguen un valor de personalización de ambos barrios.

Según el estudio realizado por Pareti, G. Henche y Salvaj (2018), la creación de las marcas Barrio de Las Letras y Barrio Italia conciben los barrios/destinos como una marca consiguiendo:

- Identificación de la zona o territorio o barrio de Madrid y Santiago de Chile (los dos barrios tienen una clara delimitación geográfica), tal como recoge la Figura №1.

- Utilidad de selección o elección por parte de los usuarios: sus nombres se identifican con un barrio histórico y literario (Barrio de Las Letras) y un barrio histórico relacionado con la tradición de la comunidad italiana ubicada en el mismo relacionada con el comercio (Barrio Italia).

- Garantía: la marca representa una expectativa de recursos a encontrar por parte de los posibles consumidores. En el caso de Barrio de Las Letras se trata de recursos relacionados con la literatura, el arte, la historia y el comercio tradicional y en el caso de Barrio Italia se trata de recursos relacionados con la historia, las antigüedades, el comercio tradicional, los patios antiguos donde se encuentran los negocios y la oferta gastronómica (Véase Figura $\mathrm{N}^{\circ} 2$ con los logos de las dos asociaciones).

- Valor de personalización: este valor se consigue en los dos barrios gracias a la existencia de pequeños comercios, anticuarios, galerías de arte, pequeños restaurantes que ofrecen productos y servicios personalizados fuera de la estandarización de los servicios masivos y del comercio "main street".

Estos comercios no solo forman parte del patrimonio histórico y cultural de la ciudad, sino que además cada vez adquieren mayor reconocimiento por ser capaces de adaptarse a los nuevos tiempos, sin perder de vista la tradición que los sustenta. Partiendo de esa base y teniendo en cuenta que lo "vintage" y lo "retro" están más de moda que nunca, estos establecimientos tienen actualmente un gran potencial y no cesan en su propósito de ensalzar los valores los comercios con larga vida, esos que permiten hacer un viaje en el tiempo a través de productos, objetos, olores y sabores (Véase Figura $\mathrm{N}^{\circ} 3$, con comercios de los barrios y el uso de la marca por parte de estos).

- Valor lúdico: en el caso del Barrio de Las Letras y Barrio Italia se generan experiencias relacionadas con eventos culturales, gastronómicos, artísticos y literarios (véase Figura $N^{\circ} 3$, que recoge algunas de las actividades lúdicas generadas por ambas asociaciones de comerciantes y Figura $\mathrm{N}^{\circ} 4$, que recoge la información de la página web de las dos Asociaciones de comerciantes).

Bajo las marcas Barrio de Las Letras y Barrio Italia, se crea una marca cuya finalidad es promocionar el atractivo de un barrio del centro de Madrid y Santiago de Chile e impulsar la actividad cultural, comercial y de ocio de este.

La oferta cultural, comercial y de ocio de dos barrios históricos con alto contenido cultural como lo son Barrio de las Letras y de Barrio Italia supone una adaptación y remodelación de un casco histórico que oferta nuevas experiencias a los turistas con nuevas necesidades y, a todo 
ello, ha contribuido el asociacionismo y las redes de colaboración del pequeño comercio emprendedor de la zona, junto con instituciones culturales ubicadas en dicho barrio.

Tanto Barrio de las Letras como Barrio Italia tienen como eje común, su posicionamiento basado en tres ítems principales: Comercio, Cultura y Turismo, resultando ser referentes al momento de hablar de barrios históricos tanto en Chile como en España.

Figura $N^{\circ} 1$

Mapas de ubicación: oferta comercial y cultural de Barrio de Las Letras y Barrio Italia

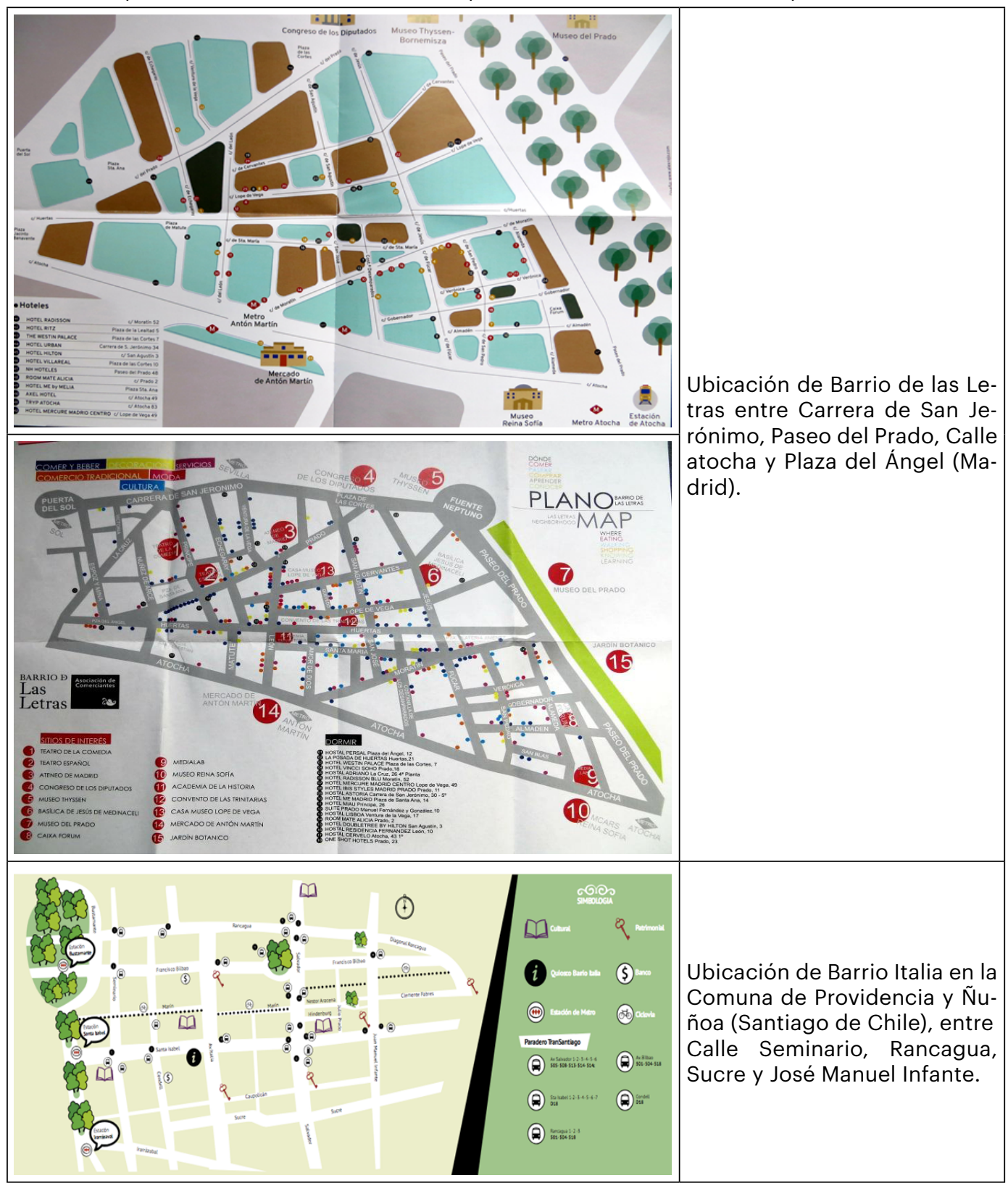

Fuente: www.barrioletras.com, Página oficial del Barrio de las Letras y http://www.barrioitalia.com, Página oficial del Barrio Italia (2019). 
Figura $\mathrm{N}^{\circ} 2$

Imagen identificativa de las Asociaciones de comerciantes del Barrio de Las Letras (Madrid)

y Barrio Italia (Santiago de Chile)

\begin{tabular}{|c|c|}
\hline Barrio de Las Letras (Madrid) & Barrio Italia (Santiago de Chile) \\
\hline BARRIO E & \\
\hline Tetras &
\end{tabular}

Fuente: Elaboración propia.

El Barrio de Las Letras se sitúa en el centro de Madrid, es miembro de la Confederación de Cascos Históricos (COCAHI) y tiene un vínculo con Cervantes, ya que allí es donde vivió y murió. Además, en el barrio nacieron los corrales de comedias, siendo un lugar icónico de la historia de la literatura universal. En la actualidad, museos, galerías, restaurantes, pequeñas y originales tiendas, un mercado de abastos tradicional y una muy variada oferta de bares, renuevan la imagen de la zona, no solo para seducir a los turistas sino también a los madrileños.

El análisis descriptivo realizado por G. Henche y Salvaj (2017) arrojaba diferentes resultados del perfil de los negocios, relatando el tamaño pequeño de los mismos (media de trabajadores son 7, si bien la mayor parte de los negocios tienen dos o tres empleados). Otro dato destacable es que el $65,78 \%$ de los negocios son gestionados por personas con estudios universitarios y un $23,53 \%$ poseen estudios secundarios.

La oferta comercial consiste en pequeñas tiendas comerciales (95 respuestas), con 35\% dedicado a servicios gastronómicos (67 respuestas), 10\% a servicios diversos (19 respuestas) y $5 \%$ a alojamiento (9 respuestas). Los establecimientos comerciales que crean la identidad del barrio en su mayoría se asocian con historia, arte y cultura.

Varias tiendas especializadas hacen referencia la historia y cultura local, como tiendas de anticuarios (casi 10\%), librerías (más del 6\%), galerías de arte (casi 16\%) y tiendas de moda y la joyería (casi un 25\%), donde varios establecimientos poseen sus propios talleres en el mismo lugar donde venden sus productos.

Respecto al uso de logo de la marca, es destacable que a finales de 2015 casi la mitad de los asociados no poseían identificación de la marca en sus locales, de ahí el trabajo de la asociación por la creación de un nuevo logo más fácilmente identificable y el trabajo de creación de una pegatina identificativa y que en la actualidad muestran la mayor parte de los locales asociados (Véase Figura $\mathrm{N}^{\circ} 4$ que recoge los logos de la imagen de marca tanto del Barrio de las Letras como de Barrio Italia).

En cuanto a las acciones de comunicación cabe resaltar el alto grado de uso de instrumentos de comunicación on-line, tanto por parte de la asociación como por parte de los establecimientos, bien sean comercios, restaurantes o galerías de arte. La página Web, Facebook, el correo 
electrónico e Instagram, son los principales medios de comunicación con el mercado usados por la Asociación y sus miembros (Véase Figura $\mathrm{N}^{\circ} 5$ ).

Figura $\mathrm{N}^{\circ} 3$

Ejemplos de comercios en el Barrio de Las Letras y Barrio Italia y uso del Logo como imagen identificativa del barrio.

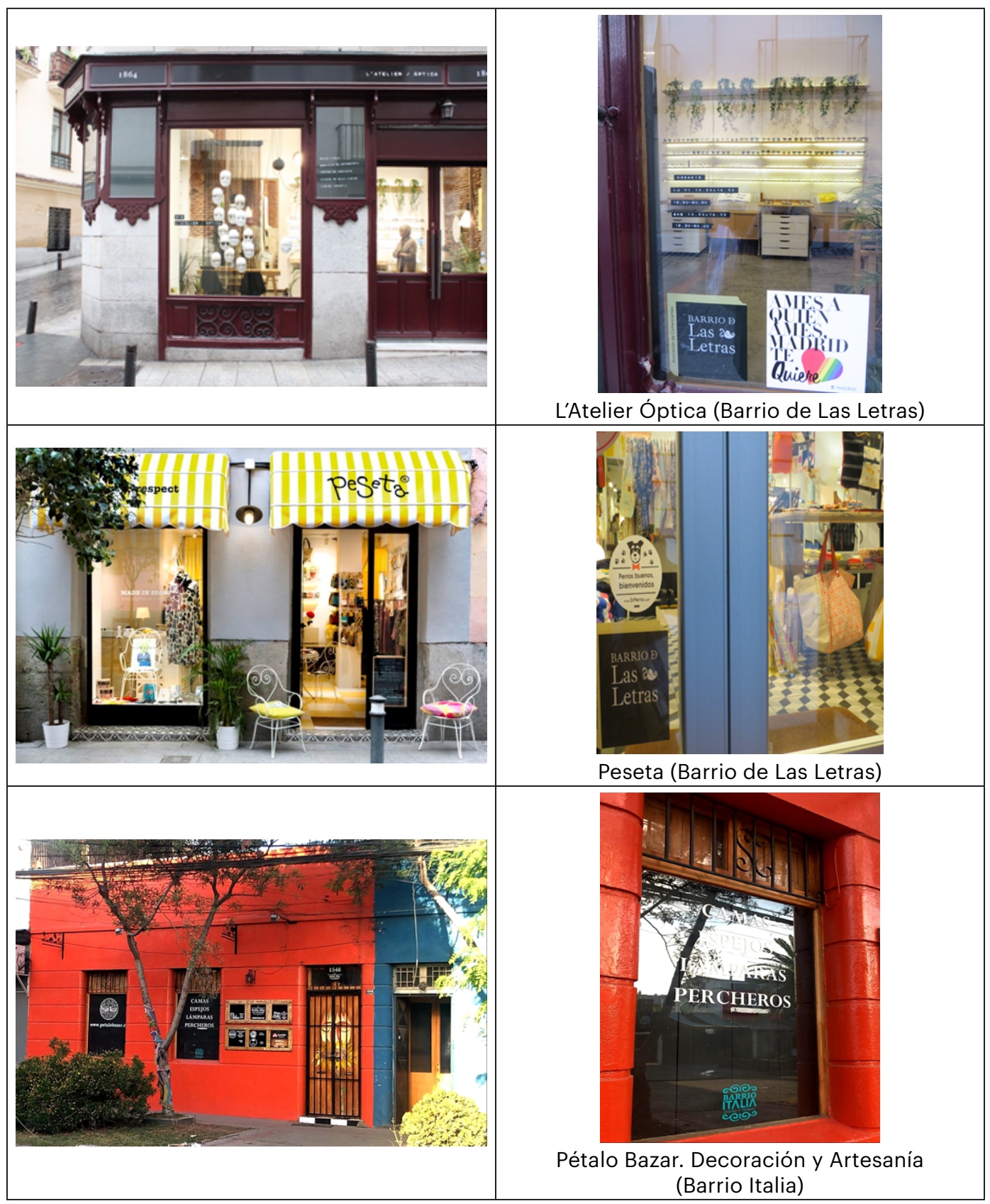



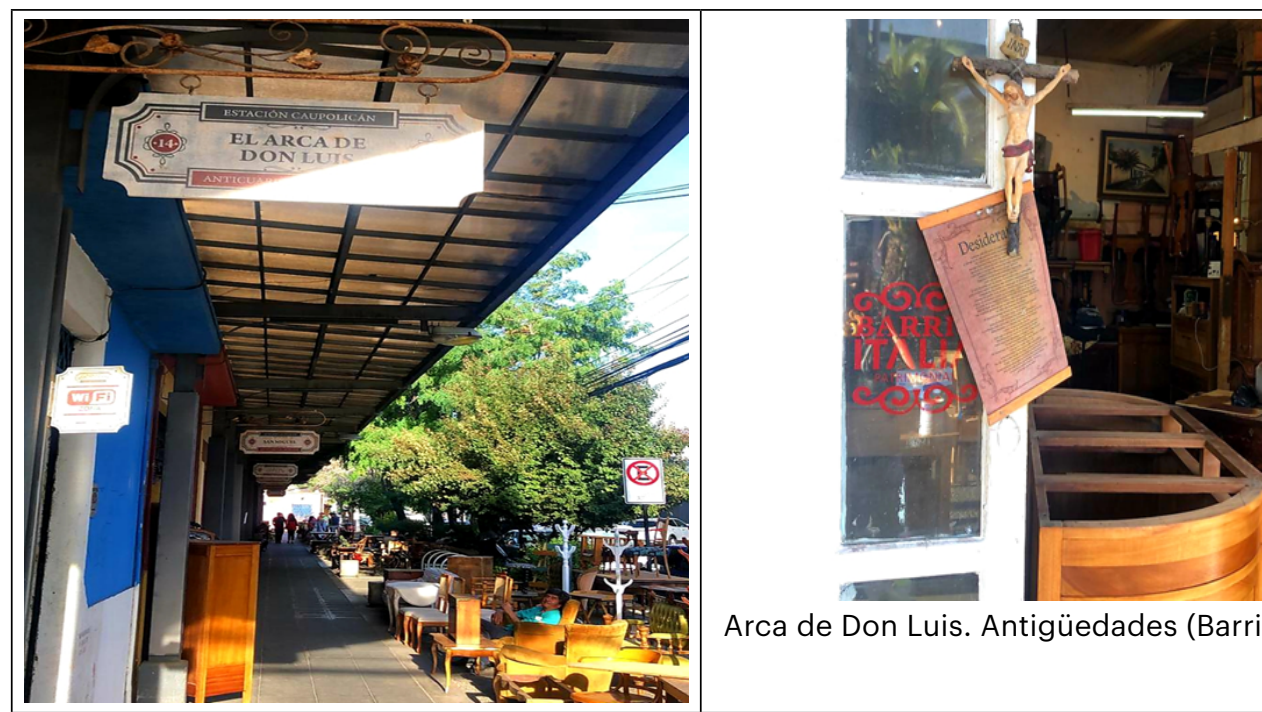

Arca de Don Luis. Antigüedades (Barrio Italia)

Fuente: Elaboración propia.

Figura $\mathrm{N}^{\circ} 4$

Uso del logo Barrio de Las Letras y Somos Italia por los establecimientos comerciales de los barrios.

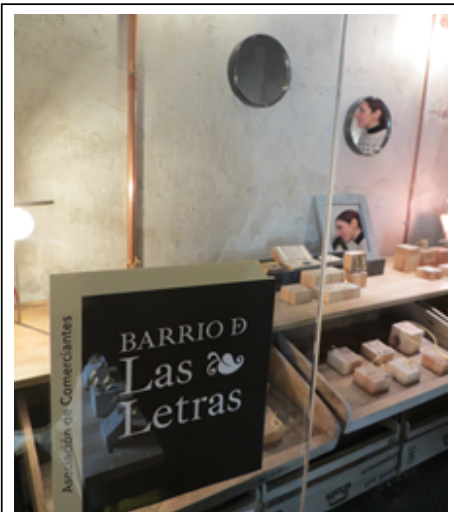

Ginger \& Velvet Taller de Joyería (Barrio de las Letras)

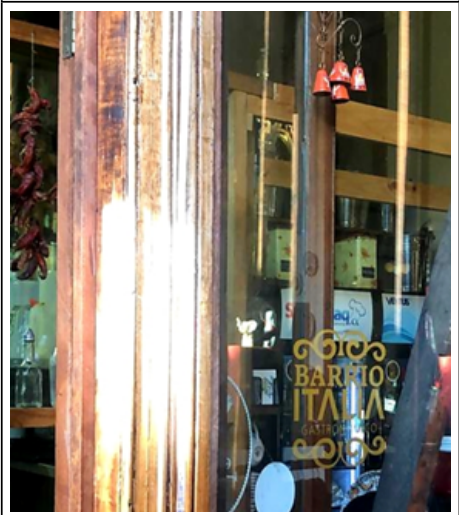

Café Silvestre (Barrio Italia)

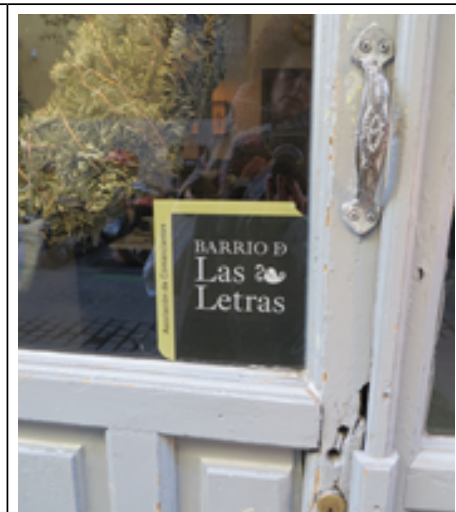

Motteau Pastelería (Barrio de Las Letras)

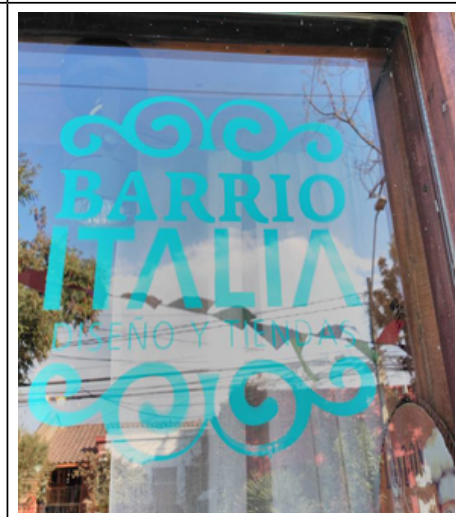

Galería Porta Azul (Barrio Italia)

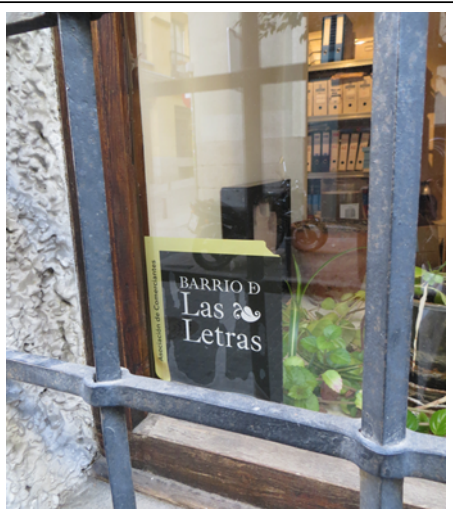

Abada Editores (Barrio de Las Letras)

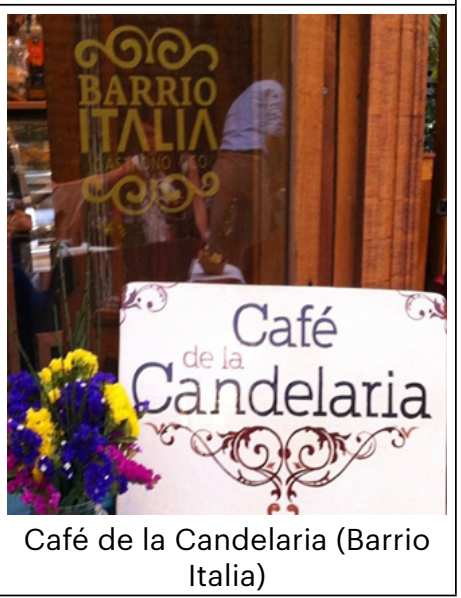

Fuente: Elaboración propia. 
Figura $\mathrm{N}^{\circ} 5$

Ejemplo de actividades creativas realizadas en el Barrio de las Letras y promocionada a través de las redes sociales son el uso de la imagen corporativa del Barrio.

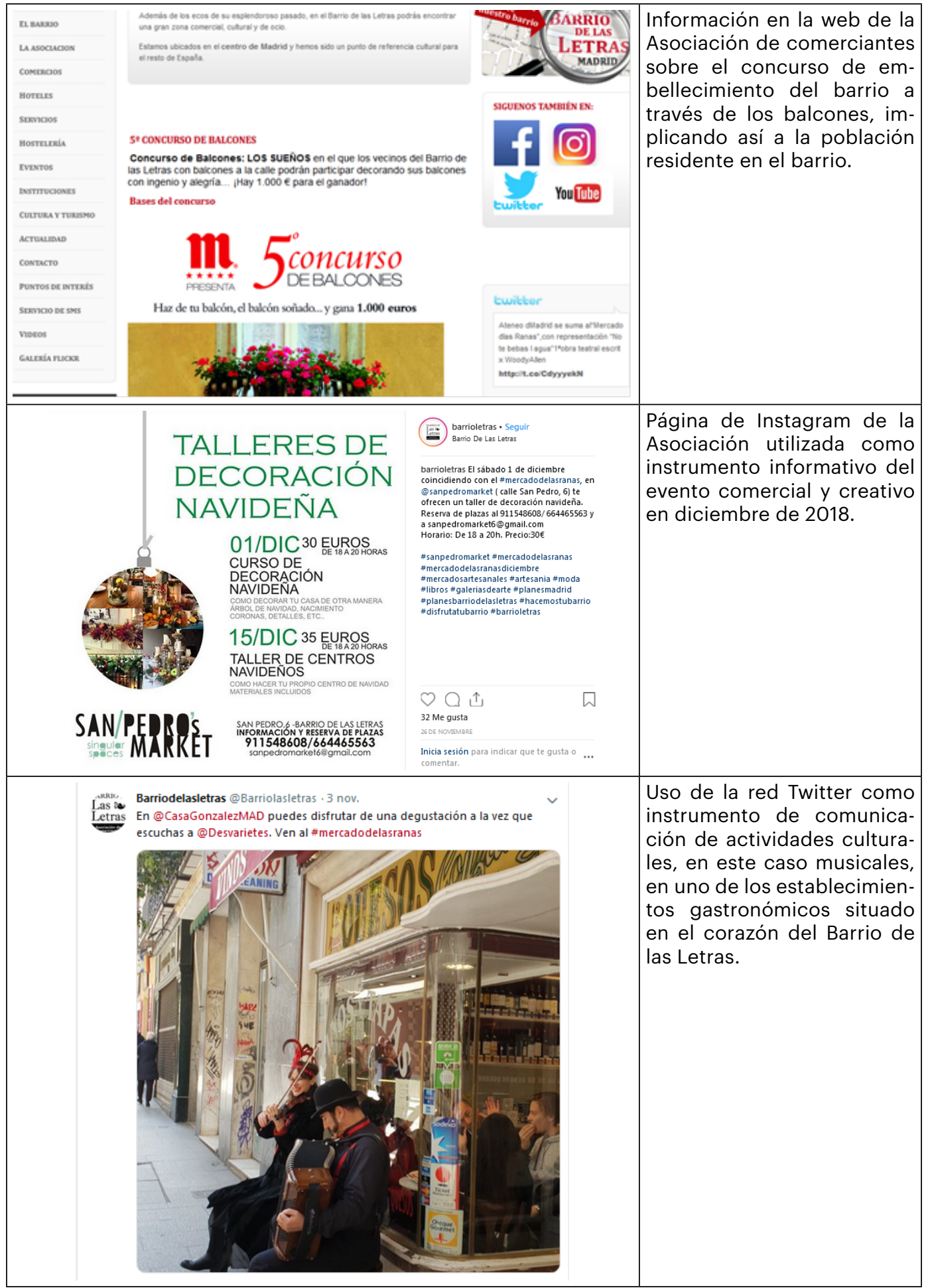

Fuente: Página oficial del Barrio de las Letras (http://www.barrioletras.com). 
Se ha establecido, además, una importante colaboración con las grandes instituciones del Barrio de las Letras: Real Academia de la Historia, Casa-Museo Lope de Vega, Teatro Español, Caixa Forum, Monasterio de las Trinitarias, Medialab, Ateneo de Madrid, etc. Dichas instituciones son un referente a nivel de recurso turístico cultural en Madrid, lo que otorga al Barrio un aire literario, al que refiere su nombre, y que es base de la experiencia ofrecida a los turistas (Véase Figura $\left.\mathrm{N}^{\circ} 6\right)$.

Figura $\mathrm{N}^{\circ} 6$

Implicación del Ateneo de Madrid en el Evento Mercado de las Ranas de febrero 2018 con la imagen de marca siempre presente

\begin{tabular}{|c|c|}
\hline $\begin{array}{l}\text { LARRIO B } \\
\text { Las } \\
\text { Letras }\end{array}$ & 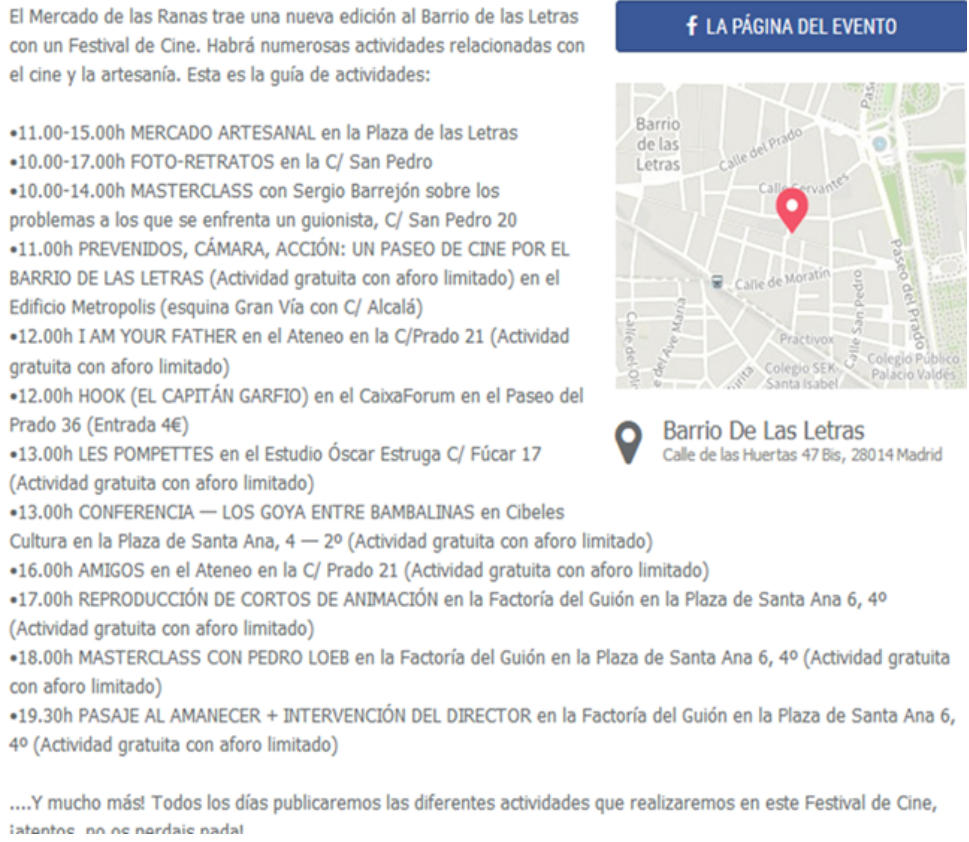 \\
\hline
\end{tabular}

Fuente: www.barrioletras.com.

Por otro lado, respecto al caso de Barrio Italia se sitúa en la comuna de Providencia en Santiago de Chile. Es un barrio histórico marcado por amplia llegada de población migrante desde inicios del siglo XX.

El desarrollo en ese entonces comenzó con la llegada de la sombrerería Girardi que se instaló en una de las esquinas más icónicas del barrio para el comercio de sombreros en aquel entonces, logrando generar un amplio espacio para que mano de obra debiese trabajar en la fábrica y por ende transitar por el barrio, como también se dio espacio a que individuos de clases más acomodadas de la época visitaran la sombrerería conociendo el barrio.

Actualmente la sombrerería no existe como tal, pero sí su antiguo edificio que fue adquirido por la Fundación Mustakis para utilizarlo como un nuevo polo de emprendimiento, dónde albergan a diversos emprendedores para actividades de co-working, universidades tienen su despacho 
de emprendimiento en aquel sitio y además existe un maker space, para que emprendedores puedan desarrollar sus prototipos.

Existe además el Teatro Italia, que es el mismo que existía en la antigüedad y que actualmente se utiliza para actividades culturales y de emprendimiento.

El análisis descriptivo realizado por Pareti, G. Henche y Salvaj (2018) muestra que el tamaño de los negocios es, en general, pequeño (la media de trabajadores fluctúa entre 1 y 3 ). Un dato destacable es que el $69 \%$ de los negocios son gestionados por personas con estudios universitarios y un $31 \%$ poseen estudios secundarios.

La oferta comercial consiste en pequeñas tiendas comerciales (197 respuestas), con $24 \%$ dedicado a servicios gastronómicos (49 respuestas), $20 \%$ a moda, textil y accesorios (40 respuestas), $12 \%$ a hogar y decoración (25 respuestas) y $13 \%$ a otros ( 27 respuestas).

Los establecimientos comerciales que crean la identidad del barrio en su mayoría se asocian con alimentación, moda, textil y accesorios junto con hogar, decoración y antigüedades.

En cuanto a las acciones de comunicación, al igual que en Barrio de las Letras, resalta el alto grado de uso de instrumentos de comunicación on-line, tanto por parte de la asociación como por parte de los establecimientos, bien sean comercios, restaurantes o galerías de arte. La página Web, Facebook, el correo electrónico e Instagram, son los principales medios de comunicación con el mercado usados por la Asociación y sus miembros (Véase Figura №7). Tanto Barrio de Las Letras como Barrio Italia, realizan multitud de actividades comerciales y culturales dirigidas a la creación de marca de barrio asociada a dichas actividades relacionadas con el pequeño comercio, el diseño, la literatura y la cultura en general.

Desde la Asociación Barrio de Las Letras se promueven múltiples actividades y campañas de comunicación que muestren a los vecinos, a los visitantes y a los turistas la rica oferta del Barrio de Las Letras. Según el estudio realizado (G. Henche \& Salvaj, 2017), las principales acciones comerciales y culturales de los últimos años son el Mercado de Las Ranas (cada primer sábado de mes los comercios sacan su actividad a la calle), Decoacción (evento anual donde anticuarios de toda España toman las calles del Barrio de Las Letras y los negocios e instituciones culturales realizan intervenciones culturales y de diseño)y La Noche de los Libros (actividades en librerías, actos literarios, teatralización en la calle).

En el caso de Barrio Italia se promueven actividades también para darle dinamismo al barrio y hacerlo más interesante, las principales acciones comerciales y culturales de los últimos años son el Mercado Italia, la Ruta del Café y del Té (Se potencia disfrutar tiempo agradable en la diversa oferta de cafés que posee el barrio), la ruta del Vino y la Cerveza (Se potencia disfrutar tiempo agradable en la diversa oferta de bares, restaurantes, cervecerías artesanales que posee el barrio), Jazz y Vino (En las calles principales del barrio artistas del jazz comparten su música junto a diversos puestos de viñas pertenecientes al movimiento de viñateros independientes), Poesía y Literatura (Es una feria literaria con cuentacuentos, firma de libros al aire libre). 
Figura $\mathrm{N}^{\circ} 7$

Actividades creativas realizadas en el Barrio Italia y promocionada a través de las redes sociales son el uso de la imagen corporativa del barrio

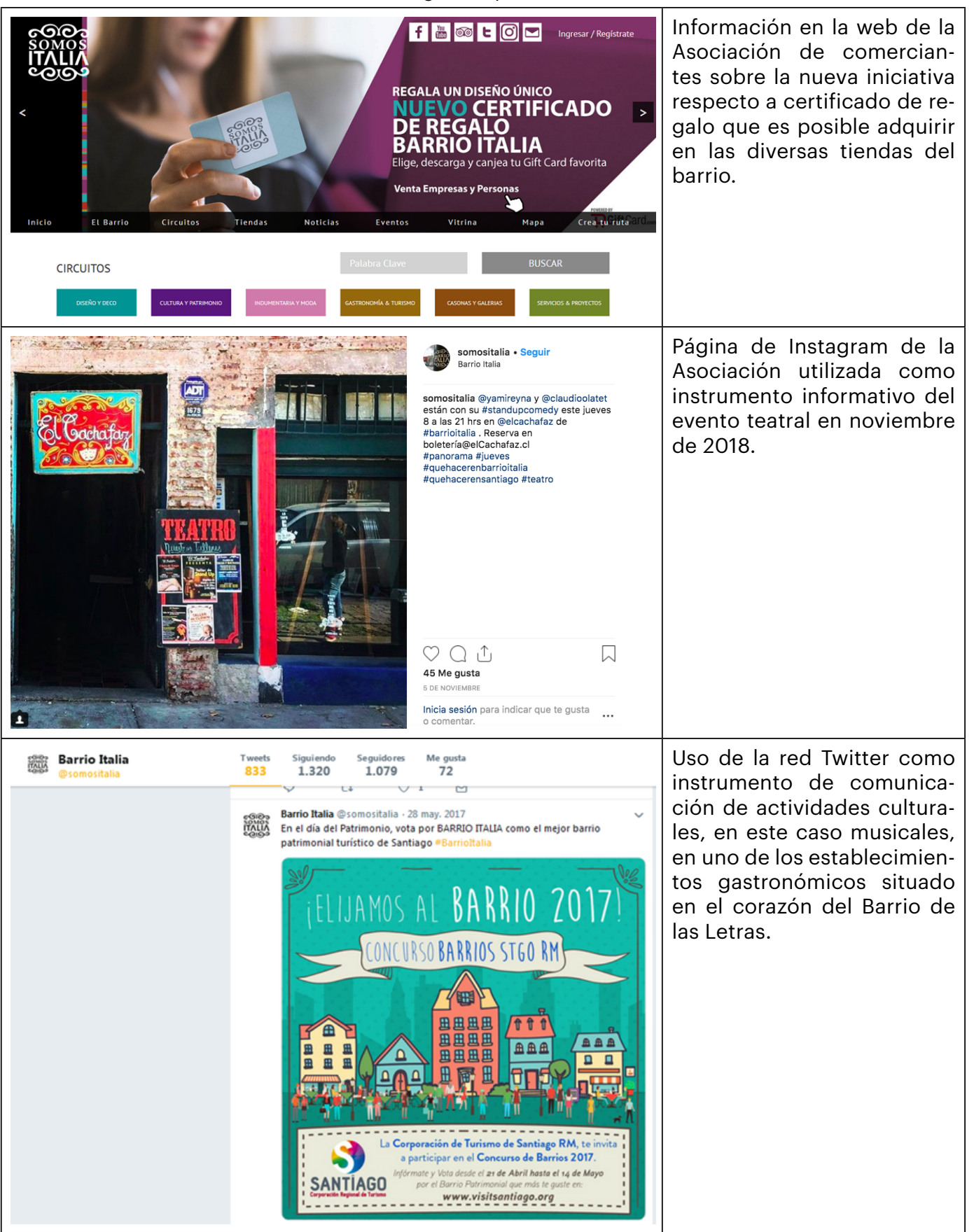

Fuente: Página oficial de Barrio Italia (hhttp://www.barrioitalia.com/).

Todas las actividades descritas, y recogidas en la figura $\mathrm{N}^{\circ} 8$, se llevan a la práctica de modo colaborativo y planificado, apoyando así la generación de una imagen de marca o destino bien percibida y posicionada por los consumidores. 
Así, el trabajo de investigación realizado en Barrio Italia y Barrio de las Letras viene a describir esa colaboración y planificación para la creación de una marca de "barrio destino" dentro de los destinos de turismo histórico y cultural

\section{Conclusiones}

La presente investigación se basa en la gestión del pequeño comercio y de proximidad como estrategia de mantención de los valores culturales en barrio históricos, mejorando la gestión del patrimonio y poniéndolo en valor, gracias a la generación de una imagen de marca de destino.

Los casos de estudio analizados, Barrio Italia y Barrio de Las Letras, han sido seleccionados por ser barrios que están trabajando en la creación de identidad de destino, para conseguir la conservación y sostenibilidad del comercio y el patrimonio de estos.

Todo el proceso de generación de identidad está enfocado al nuevo turista que busca experiencias y autenticidad y singularidad en los destinos turísticos.

Esa generación de identidad en los barrios analizados es un elemento fundamental para mantener sus recursos históricos, buscando la transformación en destinos turísticos, gracias al fortalecimiento del asociacionismo, la cooperación y las redes entre los emprendedores de los dos barrios históricos estudiados.

La investigación evidencia que un trabajo colaborativo resulta mucho más fructífero y sostenible que si las partes trabajan de forma independiente. Dicho trabajo asociacionista, fomenta la innovación y la creatividad de sus partes, además genera sentimiento de pertenencia y consolidación de imagen de destino.

Analizada la imagen de marca Barrio de Las Letras y Barrio Italia, se puede afirmar que se ha conseguido articular las bases necesarias para la creación y consolidación de dos Áreas Comerciales Urbanas, dotándolas de una estrategia común, así como de una imagen corporativa que refuerza su identidad.

El estudio muestra que para conseguir la creación marcas destino se requiere de un trabajo en múltiples dimensiones (plataformas de red, generación de servicios diferenciados, comercios especializados o de nicho, gastronomía de calidad, hostelería personalizada, entre otros); por ello, es fundamental, que exista una red de coordinación entre los comerciantes, lo cual se ve facilitado las dos asociaciones de comerciantes que asumen un papel de liderazgo y coordinación.

De acuerdo con la aproximación conceptual y la revisión de la literatura realizada en este artículo, es posible concluir que, el desarrollo y florecimiento económico de un área geográfica urbana única, que atrae turistas, requiere de una serie de actividades y estrategias de diferenciación que se generan porque existe una red colaborativa que incluye asociaciones de comerciantes, emprendedores y artistas, generando una imagen identificativa del destino. 
El estudio revela el desarrollo de espacios urbanos que tienen como objetivo ofrecer turismo de experiencias generando una ecología de redes y actividades en torno a una marca identificativa del destino, en este caso "Barrio de las Letras" y "Barrio Italia".

Figura $N^{\circ} 8$

Actividades culturales y lúdicas ofrecidas por Barrio de Las Letras y Barrio Italia para generar experiencias a los consumidores fortaleciendo su marca

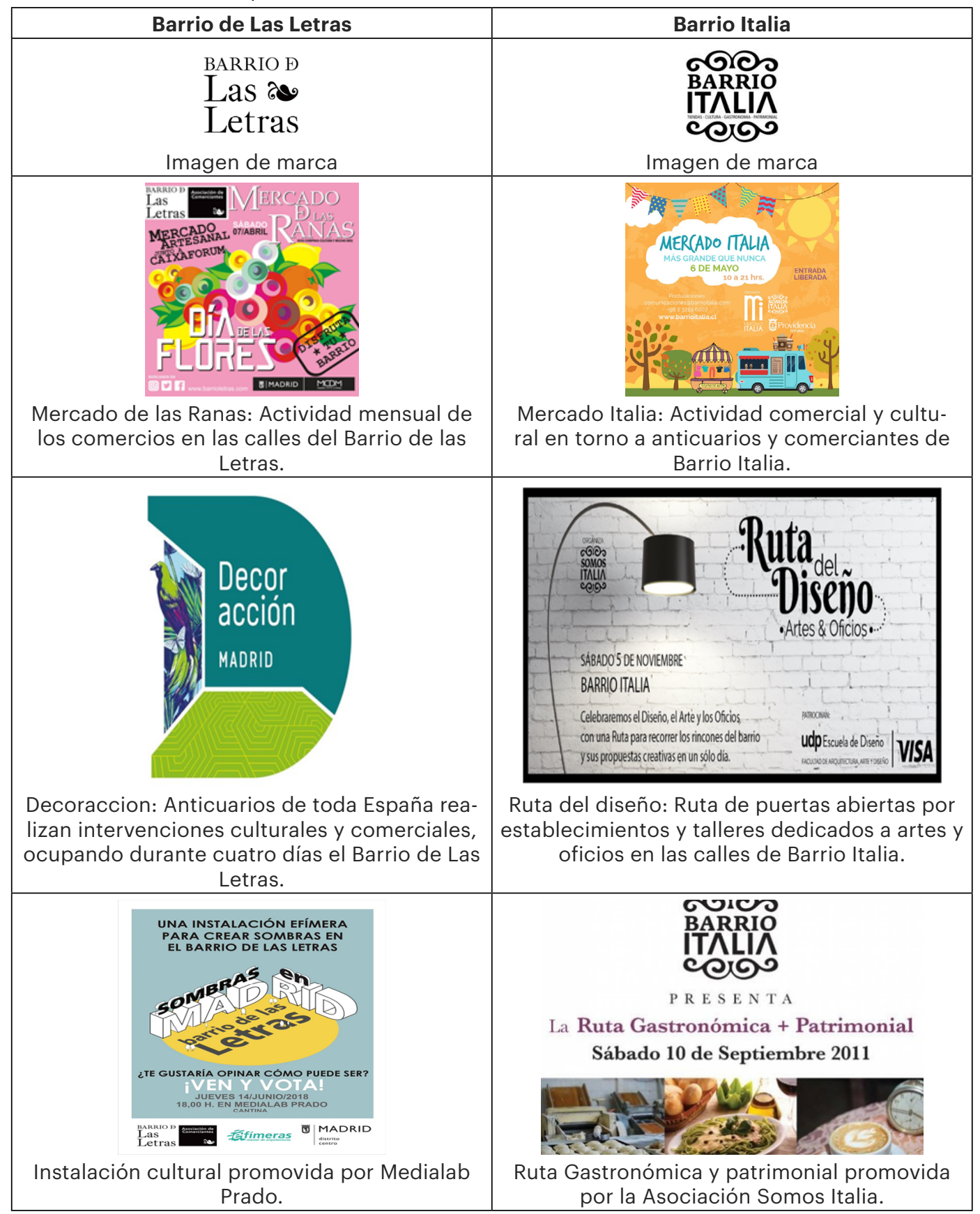

Fuente: Elaboración propia sobre información de www.barrioletras.com y http://www.barrioitalia.com/ 


\section{Referencias}

ALBORNOZ DEL VALLE, E. A., NÚÑEZ CERDA, F. J., \& MENA FRAU, C. Geomarketing: Desde una visión comercial a una aplicación social, en contextos metropolitanos. Revista De Geografía Norte Grande, 2020 No 76, p.143-167. https://doi.org/10.4067/S0718-34022020000200143

ARNABOLDI, M. y SPILLER, N. Actor-Network theory and stakeholder collaboration: The case of Cultural Districts. Tourism Management, 2011, № 32, p.641-654.

ASHWORTH, G. y KARAVATZIS, M. Beyond the logo: Brand management for cities. Brand Management, 2009, Vol. 8, No 16, p.520-531.

Asociación de Comerciantes Barrio Italia: (2019). Santiago de Chile. Disponible en Internet: http:// www.barrioitalia.com

Asociación de Comerciantes del Barrio de Las Letras: (2019). Madrid. Disponible en Internet: http://www.barrioletras.com

BAGGIO, R. y COOPER, C. Knowledge transfer in a tourism destination: the effects of a network structure. The Service Industries Journal, 2010, Vol. 10, No 30, p.1757-1771.

BAKER, M. y CAMERON, E. Critical success factors in destination marketing. Tourism and Hospitality Research, 2008, Vol. 2, № 8, p.79-97.

Bandarin, F. y Van Oers, R. The Historic Urban Landscape: managing heritage in an urban century. Oxford: Wiley-Blackwell, 2012.

BARBIERI, A., ALMEIDA SANTOS, C. y KATSUBE, Y. Volunteer tourism: On the ground observations from Rwanda, Tourism Management, 2012, № 33, p. 509-516.

BAYLISS, D. The rise of the creative city: Culture and creativity in Copenhagen. European Planning Studies, 2007, Vol. 7, No 15, p.889-903.

BIGNÉ, J.E., BORREDÁ, A. y MIQUEL, M.J. El valor del establecimiento y su relación con la imagen de marca privada: efecto moderador del conocimiento de la marca privada como oferta propia del establecimiento. Revista Europea de Dirección y Economía de la Empresa, 2013, № 22, p.1-10.

BIGNÉ, E., GARCÍA, I. y BLAS. S.The functional-psychological continuum in the cogntive image of a destination: A confirmatory analysis. Tourism Management, 2009, № 30, p.715-723.

CASTELETTI, M. y D'ACUNTO, M. Marketing per il territorio. Strategie e politiche per lo sviluppo locale nell'economia globalizzata. Milano: Franco Angeli, 2009.

CHATERINA, J. y ZORRILLA, P. Encouraging the implication of shops in the city by means of retail associations. The case of Bilbao. Cuadernos de Gestión, 2005, N 5, p.79-87. 
CHEN, C. y TSAI, D. How destination image and evaluative factors affect behavioral intentions? Tourism Management, 2007, № 28, p.1115-1122.

CRNOVRSAINT, T., MUELDER, C., FARIS, R., FELMLEE, D. y MA, K.Visualization techniques for categorical analysis of social networks with multiple edge sets. Social Networks, 2014, No 37, p. 56-64.

D`ANGELLA, F. y GO, F. Tale of two cities' collaborative tourism marketing: Towards a theory of destination stakeholder assessment. Tourism Management, 2009, № 30, p.429-440.

DICHTER, E.What is an image. Journal of Consumer Marketing, 1985, № 2, p.75-81.

DUARTE ALONSO, A. Far away from sun and beach: opportunities and challenges for cultural tourism in Cordoba, Spain. Journal of Heritage Tourism, 2015, No 10, p.21-37.

EKINCI, Y. y HOSANY, S. Destination Personality: An application of brand personality to tourism destination. Journal of Travel Research, 2016, No 45, p.127-139.

GRACI, S. Collaboration and Partnership Development for sustainable tourism. Tourism Geographies, 2013, No 15, p.25-42.

GARCÍA HENCHE, B. y SALVAJ, E. Asosiacionismo, redes y marketing en la transformación hacia el turismo experiencial. El caso del Barrio de las Letras, Madrid. Cuadernos de Turismo, 2017, No 40, p.315-338.

GLÜCKER, J. Gobernanza lateral de redes: Legitimidad y delegación relacional de la autoridad decisoria. Revista De Geografía Norte Grande, 2020, № 74, p.93-115. https://doi.org/10.4067/S071834022019000300093

HALL, C.M. y WEILER, B. Review: Special interest tourism. CABI Publishing, Newcastle, 1992.

HALLAK, R., BROWN, G. y LINDSAY, N. The place identity-Performance relationship among tourism entrepreneurs: A structural equation modeling analysis. Tourism Management, 2012, No 33, p.143-154.

HANNA, S. y ROWLEY, J. Towards a strategic place brand-management model. Journal of Marketing Management, 2011, Vol. 5-6, No 27, p.458-476.

HANKINSON, G. The management of destination brands: Five guiding principles based on recent developments in corporate branding theory. Journal of Brand Management, 2007, № 14, p.240-254.

HEERE, B., WALKER, M., YOSHIDA., M., KO, Y., JORDAN, J. y JAMES, J. Brand Community Development Through Associated Communities: Grounding Community Measurement Within Social Identity. Theory Journal of Marketing theory and practice, 2011, Vol. 4, No 19, p.407-422.

HOSANY, S., EKINCI, Y. y MUZZAFER, U. Destination image and destination personality, International Journal of Culture. Tourism and Hospitality Research, 2007, No1, p.62-81. 
JESUS, C. y FRANCO, M. Cooperation networks in tourism: A study of hotels and rural tourism establishments in an inland region of Portugal. Journal of Hospitality and Tourism Management, 2016, No 26, p.165-175.

KOTLER, P. y GERTNER, D. Country as a brand, product, and beyond: A place marketing and brand management perspective. Brand Management, 2002, Vol. 4-5, No 9, p.249-261.

KONECNIK, M. y CHERNATONY, L. Developing and applying a place brand identity model: The case of Slovenia. Journal of Business Research, 2013, N 66, p. 45-52.

LEMMETYIENEN, A. y GO, F. The key capabilities required for managing tourism business networks. Tourism Management, 2009, № 30, p.31-40.

MARIANI, M. Coordination in inter-network co-opetitition: Evidence from the tourism sector. Industrial Marketing Management, 2016, № 53, p.103-123.

MC GEHEE, N. y ANDERECK, K. Volunteer Tourism and the "voluntoured: The case of Tijuana, Mexico. Journal of Sustainable Tourism, 2009, № 17, p.39-51.

MENDOÇA, V., VARAJÃO, J. y OLIVEIRA, P. Cooperation Networks in the Tourism Sector: Multiplication of Business Opportunities. Procedia Computer Science, 2015, № 64, p.1172-1181.

MERINERO-RODRÍGUEZ, R. y PULIDO-FERNÁNDEZ, J.I. Analyzing relationships in tourism: A review. Tourism Management, 2016, No 54, p.122-135.

MUELLER, A. y SCHADE, M. Symbols and place identity. A semiotic approach to internal place branding-case study Bremen (Germany). Journal of Place Management and Development, 2012, No5(1) p.81-92.

PARETI, S., G. HENCHE, B. y SALVAJ, E. (2018). Importancia de las redes de colaboración en la dinamización de los barrios históricos hacia destinos de turismo experiencial. Casos de Barrio de las Letras en Madrid y Barrio Italia en Santiago de Chile. En: SOMOZA, J. De Lugar Geográfico a destino turístico. Análisis, Planificación y Gestión de los procesos generados por el turismo. León, España: Asociación de Geógrafos Españoles, 2018, P. 113-121.

¿PERLES-RIBES, J.F., RODRÍGUEZ-SÁNCHEZ, I. y RAMÓN- RODRÍGUEZ, ¿A.B. Is a cluster a necessary condition for success? The case of Benidorm. Current Issues in Tourism, 2015, Vol. 15, № 20, p.1575-1603.

QU, H., KIM., L. y IM, H. A model of destinations branding: Integrating the concepts of the branding and destination image. Tourism Management, 2011, No 32, p. 465- 476.

RICHARDS, G. El turismo y la ciudad: ¿hacia nuevos modelos? Revista CIDOB d'Afers Internacionals, 2016, No 113, p.71-87. 
RINALDI, C. y CAVICCHI, A. Cooperative behaviour and place branding: a longitudinal case study in Italy. Qualitative Market Research: An International Journal, 2016, Vol. 2, № 19, p.156-172.

ROBINSON, M. y NOVELLI, M. Niche Tourism. Contemporary issues, trends and cases. Routledge, 2005.

ROMERO-PADILLA, Y., NAVARRO-JURADO, E., \& ROMERO-MARTÍNEZ J.-M. Destinos turísticos y capital creativo: El caso de la costa del sol en el sur de España. Revista De Geografía Norte Grande, $2020, N^{\circ} 77$, p. 339-365.

RUIZ, A.V, OLARTE, R. y IGLESIAS, V. Evaluación de los destinos turísticos en función de su valor de marca. Actas del XI Encuentro de Profesores Universitarios de Marketing, Valladolid, 1999, p. 427-450.

SÁNCHEZ, I. y BIGNÉ, J.E. Evaluación de la imagen de destinos turísticos una aplicación metodológica en la Comunidad Valenciana. Revista Europea de Dirección y Economía de la Empresa, 2001, Vol. 3, No 10, p.189-200.

SAN MARTÍN, H. y RODRÍGUEZ DEL BOSQUE, I. Exploring the cognitive-affective nature of destination image and the role of psychological factors in its formation. Tourism Management, 2008, No 29, p.263-277.

SARANIEMI, S. y KOMPPULA, R. The development of a destination brand identity: a story of stakeholder collaboration. Current Issues in Tourism, 2007.

SOTIRIADIS, M. y LOEDOLFF, C. Nature-Based Visitor Attractions and Alliances/Partnerships: Suggesting a Collaboration Framework and the Factors Determining Effectiveness. Journal of Human Ecology, 2015, Vol. 1-2, No 49, p.89-101.

TIMUR, S. y GETZ, D. A network perspective on managing stakeholders for sustainable urban tourism. International Journal of Hospitality Management, 2008, Vol. 4, № 20, p.445-461.

VANOLO, A. The image of the creativity city: Some reflections on urban branding in Turin. Cities, $2008, N^{\circ} 25$, p.370-382.

VARDA, D. y RETRUM, J. Collaborative Performance as a Function of Network Members' Perceptions of Success. Public Performance \& Management Review, 2015, Vol. 4, No 38, p.632-653.

VIDAL, M. Intangible heritage tourism and identity. Tourism Management, 2008, №29, p.807-810.

WARNABY, G. y MEDWAY, D. What about the "place" in place marketing?. Marketing Theory, 2013, Vol. 3, No 13, p. 345-363.

WEARING, S. Volunteer Tourism. Experiences that make a difference. CABI Publishing. Wallingford, 2001. 
Prácticas Asociacionistas como estrategias de revitalización de la imagen de marca de un distrito turístico cultural. Caso de Barrio de Las Letras en Madrid y Barrio Italia en Santiago de Chile

ZACH, F. y HILL, T.L. Network, knowledge and relationship impacts on innovation in tourism destinations. Tourism Management, 2017, № 62, p.196-207.

ZENCKER, S. Who's your target? The creative class as a target group for place branding. Journal of Place Management and Development, 2009, N², p. 23-32. 
